\title{
LA RECEPCIÓN ESPAÑOLA DE LA OBRA DE SAMUEL JOHNSON EN LAS TRADUCCIONES AL CASTELLANO ${ }^{1}$
}

\author{
María Luisa Pascual Garrido, Universidad de Córdoba, España \\ Email: fflpagam@uco.es
}

\begin{abstract}
The present study analyses the reception of Samuel Johnson in Spain through the translation of his works into Spanish. Despite the immense influence Samuel Johnson has had in the English-speaking world as one of the most significant representatives of enlightened Humanism, the knowledge of his works and his figure have been rather belated in the Hispanic world. His marked "Englishness" may be considered one of the causes why his works went unnoticed among his Spanish contemporaries and the following generations at a time when political and cultural alliances linked Spain to France rather than to Great Britain. A determining factor in the process of making Samuel Johnson better-known in Spain has been the development of English Studies as an academic discipline, especially since the 1980's. The second important factor is the availability of Spanish translations of the famous biography signed by James Boswell.

Keywords: Samuel Johnson, Spanish reception, Spanish translations.

Title in English: Spanish Reception of the Work of Samuel Johnson in Spanish Translations.

Resumen: El presente estudio analiza la recepción de la obra de Samuel Johnson en España a través de las traducciones al castellano. Pese a la inmensa influencia de la que goza Samuel Johnson en el mundo angloparlante como máximo representante del humanismo ilustrado, la difusión tanto del autor como de su obra ha sido tardía en el ámbito hispánico. Su marcado carácter "inglés" puede considerarse como una de las causas del aparente desinterés que su obra despertó entre sus coetáneos y las generaciones inmediatamente posteriores en una época en las que las alianzas políticas y culturales ligaban España a Francia. Un factor determinante en la divulgación de la obra de Johnson ha sido el desarrollo como disciplina académica de los Estudios de Filología inglesa, en especial a partir de la década de 1980. El segundo factor es la aparición de varias traducciones españolas de la famosa biografía sobre la vida de Johnson firmada por James Boswell. Palabras claves: Samuel Johnson, recepción española, traducciones españolas.
\end{abstract}

\section{INTRODUCCIÓN}

La influencia de Samuel Johnson en la cultura anglófona es de tal calibre que en la historia literaria se alude a su época como la Era de Johnson. El reconocimiento a la figura

Date of reception: 7 July 2010

Date of acceptance: 23 September 2010

Odisea, n ${ }^{\circ} 11$, ISSN 1578-3820, 2010, 329-342 
de Johnson como erudito enciclopedista y gran hombre de Letras trasciende el ámbito estrictamente académico y como indicio de ello, suele decirse que, junto a Shakespeare, Johnson es el autor más citado en lengua inglesa. Sus aforismos forman ya parte del acervo cultural británico.

Samuel Johnson (1709-1784), sin duda, uno de los intelectuales más admirados de la Ilustración en Gran Bretaña destacó escritor y crítico literario, ensayista y lexicógrafo. El personaje alcanzó notoriedad pública tanto por su obra escrita como por sus grandes dotes de conversador y una personalidad algo excéntrica, facetas que James Boswell se dedicó a engrandecer en su biografía sobre el autor, The Life of Samuel Johnson (1791). No en vano, Johnson congregó a su alrededor a notables representantes de las artes, la filosofía, la historia y la política de su tiempo ${ }^{2}$ pero, como muchos autores han repetido, la leyenda de Johnson ha eclipsado en determinados momentos la relevancia de su obra.

Con motivo del tercer centenario de su nacimiento el calendario de 2009 estuvo repleto de eventos en memoria del célebre polígrafo tanto en Gran Bretaña como en otros países de habla inglesa. Sin embargo, en España este aniversario pasó completamente inadvertido y es que la recepción de Johnson aquí ha sido tardía e incompleta.

La intención de este artículo es esbozar de manera breve la acogida que ha tenido Johnson a través de la traducción e intentar explicar las razones de una demorada y algo inconsistente recepción de su obra en España. Me refiero a que, paradójicamente, la obra de Johnson más difundida en traducción en España, The History of Rasselas, Prince of Abissinia (1759) no es a juicio de la crítica lo más meritorio de su producción y su obra poética es bastante reducida. Aunque Rasselas rezuma el talante sentencioso y moralizante que caracteriza a toda su obra y haya gozado de gran popularidad en el ámbito angloparlante ${ }^{3}$ es su obra crítica y ensayística, la más científica, la que en cambio se considera su mayor contribución a las Humanidades y esta es la que curiosamente queda silenciada hasta finales del s. XX y principios del XXI.

Aunque pueda parecer superfluo repasar los grandes hitos en la trayectoria de Johnson, los apuntaré brevemente con el fin de poder establecer qué se ha recibido a través de la traducción de su propia obra en España y hasta dónde ha llegado por ésta u otras vías - por ejemplo, a través de la biografía de Boswell- su predicamento como autor y crítico ilustrado.

\footnotetext{
2 Johnson perteneció al Literary Club que junto a Joshua Reynolds fundó de 1764. A él acudían algunos de los artistas y pensadores más influyentes de su época: el dramaturgo Oliver Goldsmith, el escritor y pensador político Edmund Burke, el historiador Edward Gibbon, el actor y dramaturgo David Garrick o el filósofo-economista Adam Smith entre otros. Aunque se trataba de una tertulia literaria, en vida de Johnson (hasta 1784) el Club llegó a ampliar su número a 40 socios e integraba una variedad de personalidades y profesionales --escritores, artistas, filósofos, juristas, médicos, obispos, y políticos-- de aquella época. Johnson gozaba de gran prestigio y se puede afirmar era el foco de atención de aquellas reuniones vespertinas y aunque no siempre acudía a las sesiones sus opiniones tenían un notable eco entre sus ilustres contemporáneos.

3 Según W.J. Bate (1977) la obra en inglés se ha editado cada año desde su primera publicación y tuvo traducciones a otras lenguas en fechas muy tempranas: al francés y al holandés en 1760, al aleman en 1762, al ruso y al italiano en 1764, y ya en 1798 al español.
} 


\section{LOS LOGROS DE SAMUEL JOHNSON Y SU TRADUCCIÓN EN ESPAÑOL}

Samuel Johnson fue un verdadero "profeta en su tierra" y cosechó el reconocimiento a su labor en vida, al recibir de modo honorífico los títulos universitarios que en su juventud no logró ${ }^{4}$. Además en 1762 le fue concedida una pensión anual de 300 libras, no por lo que debía hacer "sino por lo que ya había hecho". A la edad de 53 años, Samuel Johnson había ya publicado, entre otras obras, el Diccionario de la Lengua inglesa (Dictionary of the English Language (1755)), resultado de una tediosa tarea de compilación (más 40.000 entradas y 114.000 citas de autores (Bate 1978:24)) a lo largo de algo más de ocho años. Esta obra cumbre de la lexicografía tuvo numerosas reediciones y constituyó la base para los diccionarios en lengua inglesa publicados posteriormente.

Además, Johnson se había consagrado al ensayo periodístico en el que se inició tras su llegada a Londres en 1738 escribiendo para The Gentleman's Magazine artículos de diversa índole, los Debates Parlamentarios y más tarde, varios panfletos antigubernamentales. Siguiendo el ejemplo de Francis Bacon, Joseph Addison y Richard Steele, quienes consiguieron popularizar este novedoso género con The Tatler y The Spectator en los inicios del siglo, Johnson fue uno de los autores que más elevó la categoría del ensayo periodístico en Gran Bretaña. Por su naturaleza híbrida, el ensayo podía versar tanto sobre literatura como sobre otras cuestiones de ámbito social, político, científico y filosófico. Al publicarse en "papeles periódicos", el ensayo se convirtió en el siglo XVIII en un excepcional vehículo de difusión de ideas en toda Europa, generador de opinión y debate, con fin eminentemente instructivo ${ }^{5}$.

En este sentido, Hudson (2003: 178) afirma que la obra ensayística ${ }^{6}$ de Johnson influyó enormemente en la conformación de la ideología ilustrada entre la burguesía británica. Su autoridad y prestigio en Gran Bretaña queda patente en las sucesivas ediciones que tuvo el volumen recopilatorio de The Rambler tras la primera en 1756. Pero si el ascendiente de estos escritos fue grande en vida de Johnson, su proyección posterior fue incluso mayor pues hubo más de veinte reimpresiones de The Rambler antes de 1800 y durante el siglo XIX numerosos ensayos de Johnson aparecieron antologados junto con otros célebres ejemplos del género periodístico (Korshin 1997).

En The Rambler, ideado para formar el gusto literario de su tiempo, Samuel Johnson analizaba diversas cuestiones relativas a la proliferación de un nuevo gusto por formas literarias de gran popularidad en su época como el género autobiográfico (Rambler $\mathrm{n}^{\mathrm{o}} 84$ ), o la novela (Rambler $\left.\mathrm{n}^{\circ} 4\right)$, por ejemplo. Pero además, Johnson abordó los conflictos familiares, el problema de la autoridad y la tiranía de los padres, que suponen según Korshin (1997: 51-66), el tratamiento indirecto de cuestiones políticas ${ }^{7}$. El matrimonio fue también

4 Del Trinity College de Dublín en 1765 y de la Universidad de Oxford en 1775.

5 El alcance de las opiniones e ideas vertidas en los ensayos periódicos era mucho mayor del que las tiradas pueden insinuar, pues es sabido que de manera indirecta llegaban más allá de sus primeros lectores hasta los clubes y salones donde se debatían e incluso entre personas que sin haber tenido acceso a ellos discutían las ideas propuestas.

$6 \quad$ Sus ensayos se hallan en la publicación de The Rambler entre 1750-1752, y continúan con The Adventurer (1753-54) y The Idler entre 1758 y 1760 fundamentalmente.

7 Pues aludían de manera implícita a las rebeliones jacobitas de la época, con las que al parecer Johnson simpatizaba.

Odisea, n ${ }^{\circ} 11$, ISSN 1578-3820, 2010, 329-342 
materia propia de los ensayos y aunque Johnson reservaba a la mujer un ámbito doméstico, en consonancia con el pensamiento convencional de su época, no es menos cierto que sintonizaba con la necesidad de instruir a la mujer, cuestión tan debatida en el siglo XVIII e insinuada en la novela Rasselas a través del trato igualitario que dispensa a personajes masculinos y femeninos.

Pero como ilustra la siguiente cita de Johnson: “for it is always a writer's virtue to make the world better" (Greene 1986: 427) una de las mayores preocupaciones de Johnson es la responsabilidad moral del erudito (Adventurer $\mathrm{n}^{\circ} 85$ ) como educador y guía de sus lectores. Sin duda, Johnson es ante todo un comentarista moral en su obra ensayística -en realidad, en toda su obra- donde incluso tiende al formato del sermón ${ }^{8}$ aunque evita la justificación de tipo religioso.

Hemos comentado el gran predicamento de los ensayos de Johnson en Gran Bretaña, pero ¿cuál ha sido la fortuna de esta parte fundamental de su producción en España? Los ensayos de Johnson apenas han tenido eco en traducción española a excepción, como observan algunos autores (Álvarez Barrientos 1991; Stone 2006), de dos números que se tradujeron en 1764 en El Novelero de los estrados y tertulias. Diario universal de las bagatelas, 4 y 6. El primer número seguía, según Stone, The Idler 102 (sobre la autobiografía) al parecer directamente del inglés, y el segundo es traducción de The Rambler 4, sobre la novela realista (Alvarez Barrientos 1991: 107)9 , traducido seguramente del periódico francés Journal Étranger, de la mano de Francisco Nifo. En ambos casos se silencia la autoría del polígrafo inglés (Stone 2006: 36). El número concerniente a la novela, analizaba, siguiendo a Johnson, nuevas concepciones sobre un género híbrido y escasamente valorado, el de la novela, entonces en plena evolución. La importancia de esta publicación es evidente: "Nifo está presentando las coordenadas de la novela modernas, aquella que ya se escribía en Inglaterra pero que era todavía poco conocida en España, y está proponiendo la necesidad de modernizar los modelos de imitación” (Álvarez Barrientos 1991:108).

De la producción poética de Johnson lo más valorado por la crítica es el poema London (1738), que ha sido rescatado recientemente en versión española en 2004 por Valentín Carcelén ${ }^{10}$ y junto a este, la sátira The Vanity of Human Wishes (1749), inédita hasta ahora en traducción española. En London, compuesto en imitación a la tercera sátira de Juvenal, Johnson se nos muestra desilusionado con la vida en la ciudad, y crítico con el gobierno whig y su rey, Jorge II. En este poema además, el autor inglés destila su ferviente defensa de la causa británica frente a sus rivales europeos, Francia y España. Parece comprensible

\footnotetext{
8 "Books of morality are daily written, yet its influence is still little in the world; so the ground is annually ploughed, and yet multitudes are in want of bread. But, surely, neither the labours of the moralist nor of the husbandmen are vain: let them for a while neglect their tasks, and their usefulness will be known; the wickedness that is now frequent would become universal, the bread that is now scarce would wholly fail". (The Adventurer, 137).

9 Las versiones se han atribuido a Francisco Nifo, quien escribía bajo el pseudónimo de Don Antonio Ruiz Miñondo. EL novelero de los estrados y tertulias. Diario Universal de las Bagatelas fue una publicación de innegable "valor para la difusión de la novela, tanto de modelos narrativos y de observación social como de ideas teóricas" (Álvarez Barrientos 1991:116).

10 Valentín Carcelén (1964, Albacete) es poeta, traductor (de Philip Larkin) y profesor de inglés en Secundaria. Ha publicado su obra poética en revistas literarias como Barcarola y su poesía es objeto de varias antologías poética publicadas en los últimos años.
} 
pues, que tanto por las implicaciones políticas así como por las constantes referencias locales a Inglaterra, el poema fuese considerado "intraducible" al español en el siglo XVIII.

El destino en España de The History of Rasselas, Prince of Abissinia (1759), la única novela del autor inglés, es bastante atípico si consideramos la recepción española que ha tenido la obra de Johnson en su conjunto (Pajares 1996, Bolufer, 2008). En primer lugar, El príncipe de Abisinia (1798), título de la traducción española de Inés Joyes y Blake ${ }^{11}$ fue publicada a los pocos años de la muerte de su autor, adelantándose así en ofrecer al público español la primera muestra de la obra de Johnson, el más prestigioso hombre de letras de la cultura inglesa de entonces. Asimismo, si recordamos que por lo general se accedía a las obras extranjeras a través del francés, la lengua de la cultura hegemónica, la primera traducción de Johnson puede considerarse como un trabajo pionero en su género, pues se hace directamente del texto original inglés. La edición de Joyes ha sido también única en el uso estratégico que la traductora hace del texto de Johnson, al insertar al final un escrito de su propia cosecha ("Apología de las mujeres") para elevar al ámbito público su postura sobre la educación y el papel de la mujer en la sociedad del XVIII, algo casi impensable para una mujer de entonces (Bolufer 2008).

Durante el siglo XIX, Rasselas continuó en boga y se publicaron tres traducciones en español: la editada en Londres en 1813 por el reverendo Felipe Fernández, miembro de la Sociedad Económica de Jerez de la Frontera, quien decía desconocer versión anterior a la suya; la segunda, publicada en Méjico en 1834, a cargo de Luis Cuevas; y la tercera, en versión de Marcial Busquets, impresa en Madrid y Barcelona en $1860^{12}$. Los dos primeros prólogos encarecen la obra por sus enseñanzas morales y su contenido acorde con los principios religiosos de sus lectores. En el siglo XX, Rasselas ha visto otras cinco nuevas traducciones: la de Javier Zengotita en Reguera, Barcelona en 1945; la de Mariano Vedia y Mitre en Kraft, Buenos Aires, 1951; la de Enrique Blanco (introducción de J. Martín Triana) en Felmar, Madrid de 1976, otra versión de Elvio Gandolfo en Buenos Aires en 1982, y de Pollux Hernúñez en 1991, en Alianza, Madrid. La última traducción de Rasselas se publicó en Córdoba en 2007. La interpretación de esta novela ha ido variando con los tiempos: mientras que hasta la versión de 1834 la obra era encomiada por su utilidad como "discurso metafísico sobre la inmortalidad del alma racional" (Fernández 1813) y "su moral cristiana" (Cuevas 1834) desde 1860 hasta 1945 el relato es escogido como "relato exótico" (Busquets 1860) y de "románticas andanzas" (Zengotita 1945). A partir de la edición de 1976, la obra va acompañada de introducciones filológicas y se presenta bien como uno de los modelos ensayados de la novela en el XVIII (Martín Triana 1976) o como cuento filosófico que encierra el espíritu de escéptico racionalismo y empirismo del que Johnson como autor es un excelente representante (Hernúñez 1991). En la última edición española se destaca también la lectura feminista que hace la primera traductora de Rasselas al español allá por 1798 (Pascual 2007).

\footnotetext{
11 La figura de Inés Joyes y Blake, miembro de la colonia irlandesa afincada en Málaga, ha sido estudiada por Monica Bolufer Peruga en La Vida y la escritura en el siglo XVIII: Inés Joyces: Apología de las mujeres, Valencia: Publicacións de la Universitat de Valencia, 2008. La autora destaca la aportación de esta mujer al discurso sobre el papel femenino en la sociedad del siglo XVIII en su "Apología de las mujeres", texto que se anexa a la versión traducida de Rasselas

12 En un volumen conjunto con la obra de Dumas, Los compañeros de Jehú.
} 
Un caso distinto es que el ofrece la muy demorada recepción de Johnson a España en su faceta de crítico literario. Tras el gran fracaso de la única obra dramática de Johnson, Irene (1749), el autor entendió que su genio estaba mejor aprovechado en otras ocupaciones. Y entre éstas, la más destacable es su labor de comentarista literario, vertiente que desarrollaba ya en los ensayos, y que culmina en dos obras de su madurez: Preface to the Plays of William Shakespeare (1765) y Lives of the English Poets (1781).

En el Prefacio a la obra dramática de Shakespeare Johnson realiza un ejercicio crítico que consiste en exponer tanto las virtudes de la obra dramática de Shakespeare -su prolongada popularidad en los escenarios, su capacidad mimética, la mezcla de elementos trágicos y cómico en la misma obra, y la naturalidad y modernidad de sus diálogos - como los defectos que se le podían achacar, de acuerdo con la estética neoclásica -su proclividad a deleitar sin un fin edificante claro, sus anacronismos y la insubordinación a las reglas dramáticas de tiempo y lugar. Johnson se esforzó en justificar las licencias con respecto a la unidad de espacio y tiempo, errores de tipo histórico y la rudeza del lenguaje en ocasiones, alegando que Shakespeare vivía en una Inglaterra aún lastrada por la barbarie del pasado y que en sus circunstancias, el dramaturgo hizo mucho más de lo que se cabría esperar de un hombre sin la formación clásica propia de los nobles cortesanos. Johnson apostó por declarar el genio de Shakespeare en oposición a la ortodoxia de su tiempo y en suma, es responsable hasta cierto punto de la canonización de la obra shakespeareana.

Aunque con mucho retraso, el Prefacio a Shakespeare ha conocido dos versiones: la primera en español -El Prefacio a Shakespeare (2003) - traducido por Carmen Toledano y la segunda en catalán a cargo de Stone y Vidal - Prefaci a les obres dramàtiques de William Shakespeare (2004). Mientras que la edición catalana tiene el mérito de iluminar la vida y obra de Johnson para el lector y de contextualizar la pieza en la historiografía sobre Shakespeare, la traducción al español queda algo huérfana dando por sentado un conocimiento inexistente en España sobre el lugar que ocupa Johnson en la cultura del XVIII.

Por otra parte, en Lives of the English Poets (1781), traducida por Bernd Dietz en la editorial Cátedra -Vidas de los poetas ingleses (1988)-, Johnson ofrece un semblante biográfico y el análisis de la obra de cincuenta y dos autores ingleses del XVII y XVIII. La versión de Dietz, una selección de la vida de nueve de esos poetas, marca un antes y un después al ser pionera en difundir la obra crítica de Johnson en español, y sin duda, alentando el interés de diversos especialistas en la disciplina de Filología inglesa por hacer visible la variada contribución de Johnson al saber de su tiempo (García Landa 1990).

Dada la proximidad de los autores sobre los que escribía, la valoración crítica que Johnson era bastante arriesgada. No en vano, se le ha tildado a Johnson de ser un juez demasiado parcial o dogmático en sus posturas, pues se le achaca que desprecie ideológica y moralmente a Milton, autor de El Paraíso perdido. Aunque en realidad Johnson lo elogiase como gran poeta, la crítica ha condenado la arbitrariedad en su censura moral de Milton, o que no haya sabido apreciar, por ejemplo, el frescor prerromántico que aportaba la poesía de Thomas Gray. Lo cierto es que Johnson, máximo exponente de la preceptiva neoclásica, difícilmente podría admitir o disfrutar de obras que supusieran un desvío de la estética augustana. Pero es justo reconocer, pese a todo, y considerando que el currículo escolar y universitario se ocupaba de la literatura en lenguas clásicas fundamentalmente, 
que Johnson desempeñó un papel determinante en el conocimiento y la valoración de los autores en lengua inglesa más recientes entre sus coetáneos.

Sin embargo, la obra de Johnson no se circunscribe al ámbito de la filología exclusivamente, sino que cubre otros intereses inconfundiblemente ilustrados. Ya en su juventud Johnson, deseoso de aventuras y viajes, encauza dicha fascinación mediante la lectura de narraciones de viajeros y decide acometer la traducción de A Voyage to Abyssinia (1735) que narra la experiencia del portugués Jerónimo Lobo cuya misión es la reconversión del pueblo abisinio a la ortodoxia católica. A sus 50 años, Johnson vuelve a este género y escribe Rasselas (1759), narración del viaje iniciático de un joven príncipe abisinio y de su hermana en busca de la felicidad. Por fin, en su vejez Johnson logra llevar a término la experiencia del viaje mismo, y en compañía de joven abogado escocés emprende un periplo por las Tierras Altas de Escocia y las Islas Hébridas, y compondrá en primera persona $A$ Journey to the Western Islands of Scotland (1775). Por suerte para los lectores españoles, existe una magnífica traducción y exhaustivo estudio preliminar a cargo de Agustín Coletes, El Viaje a las islas occidentales de Escocia (2006). En este relato, Johnson se nos presenta como un ávido observador científico que hace las veces de geógrafo, etnólogo, historiador, sociólogo, filósofo y lingüista todo en uno. Mediante su selección del relato de viajes, Coletes enriquece notablemente la percepción que los lectores españoles tienen hasta entonces de Johnson a través de la lectura de sus obras en traducción, la cual se ha centrado exclusivamente en la ficción y en la crítica literaria, y ha ignorado el amplio espectro de intereses que aborda Johnson en su obra.

A todo lo anterior hay que añadir otro factor determinante en la apreciación de Johnson como icono de la cultura inglesa. Me refiero al papel que desempeñan las sucesivas versiones en español de la biografía de James Boswell, The Life of Samuel Johnson (1791). La imagen de Johnson como personalidad central del XVIII inglés empezó a perfilarse entre los lectores de habla hispana gracias a la versión abreviada de Antonio Dorta de La vida del doctor Samuel Johnson (1949), publicada en Austral. La difusión de esta traducción en la segunda mitad del siglo XX, y su reedición en 1998 en Espasa ha permitido que la figura de Johnson fuese conocida, si no mediante el acceso directo a sus obras, al menos a través de las entretenidas anécdotas que ofrece el retrato pergeñado por el abogado escocés. La atracción que esta obra ha suscitado, bien sea por el interés mórbido que provoca el género biográfico, o por la calidad de la obra de Boswell, se ha avivado más si cabe en el presente siglo. En 2007 se publicaron sendas traducciones de la obra de Boswell en su totalidad. La primera, a cargo de José Miguel y Cándido Santamaría (Espasa Calpe. Madrid 2007), fue reseñada en los diarios nacionales (El País Jose $\mathrm{M}^{\mathrm{a}}$ Guelbenzu y Fernando Savater) y tuvo un evidente el impacto mediático al estar prologada por Savater. La segunda versión, de Miguel Martínez-Lage (Acantilado, Barcelona 2007), le granjeó al traductor el Premio Nacional de Traducción de 2008, con numerosas reseñas en La Vanguardia, El País y ABC, entre otros medios. En ambos casos tanto los prólogos a la traducción como las reseñas que han provocado en medios escritos destacan el lugar de honor que ocupa el excéntrico Johnson como figura hegemónica de la cultura británica, como autor canónico de extrema perspicacia, como ser humano dominado por sus debilidades, como inglés patriótico y crítico con su gobierno, como pensador conservador de un apabullante sentido común. De 
la obra de Boswell se dice que es un clásico, máximo exponente de la literatura biográfica y el mejor retrato de la sociedad y la cultura británicas del XVIII ${ }^{13}$.

El 24 de noviembre de 2009, se publicó la $1^{\text {a }}$ edición española de Political Writings, basada en el Tomo X de la edición estándar de Yale de la obra de Johnson. Este volúmen incluye "Taxation No Tyranny", una defensa de la corona británica frente a los rebeldes americanos, "Thoughts on the Late Transactions Respecting Falkland's Islands", "An Introduction to the Political State of Great Britain, " "Thoughts on the Coronation of King George III, " and "The Patriot, " uno de los textos principales de Johnson en relación a la Revolución americana. Los Escritos políticos (2009) aportarán una nueva visión a los lectores de habla hispana acerca del pensamiento de Johnson quien intentaba crear opinión acerca del gobierno whig y la monarquía, sobre el verdadero patriotismo o las relaciones entre Gran Bretaña, sus colonias y sus rivales políticos y comerciales. La obra será de especial interés para los historiadores y cualquier estudioso de las relaciones hispano-británicas del siglo XVIII.

Por otra parte, en una entrevista al Diario de Navarra (14/11/2008) Martínez-Lage, el ganador del Premino Nacional de Traducción del 2008 anunciaba la inminente traducción de una selección de aforismos y ensayos de Johnson que, por lo que he podido averiguar, aún no han visto la luz ${ }^{14}$.

Ahora cabría preguntarse ¿qué lagunas existen aún en la difusión de este gigante de la Ilustración británica en nuestra lengua? Pues bien, para un conocimiento adecuado de Johnson en España faltaría aún la traducción completa de los ensayos de The Rambler, The Idler, The Adventurer, de cuarenta y dos de las Vidas de los poetas ingleses, y del poema "The Vanity of Human Wishes" entre otras obras de relevancia.

En suma, podemos afirmar que la recepción de Johnson en España ha sido muy tardía e inconsistente, pues frente a la importancia de su obra ensayística y crítica, silenciada hasta 1988, Rasselas, la novela filosófica del autor ha tenido hasta diez versiones diferentes en español. Consideramos a continuación las causas de esta incompleta y lentísima recepción de Samuel Johnson a través de las traducciones españolas.

\footnotetext{
13 "Es un libro prodigioso que conviene saborear sin prisas para comprobar que no ha envejecido y es tan fresco como el periódico de esta mañana", Lluís Foix, La Vanguardia; “Vida de Samuel Johnson se sitúa entre los libros más relevantes del saber humano, junto al Quijote o el «corpus shakesperiano»". Sergi Doria, $A B C$; "Vida de Samuel Johnson es un libro imprescindible de la literatura universal". Josep Massot, La Vanguardia; "Hay un antes y un después de Vida de Samuel Johnson, un modelo sin parangón en el arte de la biografía", Luis Alberto de Cuenca, $A B C$; "Éste es un libro único, ejemplar y genial. Ningún lector culto puede permitirse el lujo de prescindir de él", José María Guelbenzu, El País; "Una de las mejores biografías de la historia y una crónica extraordinariamente vívida de la escena cultural londinense del siglo XVIII", Abel Grau, El País; "Un libro, en fin, para descubrir y disfrutar por tiempo indefinido", Carles Barba, Qué Leer; "Uno de los libros más impresionantes y divertidos no sólo de la literatura inglesa sino europea. Vida de Samuel Johnson es arte de primera magnitud", Xavier Pla, La Vanguardia.

14 Martínez-Lage en entrevista concedida en El Diario de Mallorca (15/02/2009) también habló de la próxima aparición de su traducción de El Diario de un viaje a las Hébridas de Boswell.
}

Odisea, $n^{\circ} 11$, ISSN 1578-3820, 2010, 329-342 


\section{CONCLUSIONES: LAS CAUSAS DE UNA RECEPCIÓN TARDÍA E INCOMPLETA DE JOHNSON EN ESPAÑA.}

La recepción de Johnson en España sigue las tendencias generales aplicables a la historia de la traducción del inglés al español.

En primer, hay que recordar que durante el siglo XVIII, la traducción es percibida en España como vehículo de ideas, sobre todo de carácter moral, lo que refuerza la naturaleza didáctica de la obra literaria y de la traducción, de ahí el éxito inicial de Rasselas, que tiene un lugar privilegiado en la recepción española de Johnson como relato edificante para la moral de sus lectores.

En segundo lugar, revisada la historia de la traducción en España (Ruiz Casanova 2000, Lafarga y Pegenaute 2004, Pajares 2006) ${ }^{15}$ es obvio que el afrancesamiento de la cultura española del siglo XVIII tuvo como consecuencia la escasa presencia de la obra de autores ingleses, que apenas se traducen durante el mismo periodo. Aguilar Piñal (1991: 1999), estima que durante el XVIII el 65\% de la obras traducidas eran de autores franceses frente al $7.3 \%$ correspondiente a traducciones del inglés, muy por detrás de las traducciones procedentes del italiano, que constituían el $23 \%$.

Según Ruiz Casanova (2000: 375-78) a finales del XVIII esta tendencia amaina y empieza a importarse, en la mayoría de los casos por mediación de versiones francesas, mayor número de obras de autores ingleses: la obra de Samuel Richardson (Pamela Andrews o la virtud premiada de García Malo, 1794), los poemas de Ossian (traducidos por José Alonso Ortiz en 1788 y Pedro Montegón en 1800), el Paraíso perdido de Milton (aunque traducido fragmentariamente por Luzán, Jovellanos y Cadalso antes) de Juan Escoiquiz (1812), y las obras selectas de Edward Young (1789-1790) por el mismo traductor. En cambio, como excepción que confirma la regla de la traducción mediada, Leandro Fernández de Moratín e Inés Joyes y Blake traducen respectivamente el Hamlet de Shakespeare y Rasselas de Johnson, ambas publicadas en 1798 tomando como TO el inglés, lo que revela también el inicio de una actividad traductora sin intermediación de la cultura francesa.

Por otra parte, $\mathrm{y}$ debido a la popularidad que adquiere la novela como género literario es natural que sea Gran Bretaña, la nación donde se desarrollan con más éxito nuevas fórmulas novelísticas, la gran exportadora de ficción al resto de Europa durante el XVIII y el XIX. En España, este flujo llega tarde y tímidamente en la última década del XVIII, y tienen mayor aceptación Pamela y Clarissa de Richardson ${ }^{16}$ y la Amelia de Fielding ${ }^{17}$, novelas

\footnotetext{
15 Ruiz Casanova, José Francisco, Aproximación a una historia de la traducción en España, Madrid: Cátedra, 2000, pp. 345-382 "Literatura y traducción dieciochescas"; Lafarga, Francisco y Luis Pegenaute (eds.) Historia de la traducción en España, Salamanca. Ambos Mundos, 2004, pp. 209-320; Pajares, Pajares, Eterio. La novela inglesa en traducción al español durante los siglos XVIII y XIX: aproximación bibliográfica, Barcelona: PPU, 2006)

16 Ignacio García Malo traduce del francés Pamela (1794 y 1798). José Marcos Gutiérrez traduce Clara Harlowe (1794-96) y Historia del caballero Carlos Grandison (1798).

17 Amelia se publica en español en 1795 (traducido por D.R.A.D.Q.) e Ignacio de Ordejón traduce del francés Tom Jones (1796).
} 
sentimentales y picarescas. Las novelas de Defoe ${ }^{18}$ y Swift ${ }^{19}$, consideradas como relatos de aventuras, no son traducidas hasta el XIX, periodo marcado en su segunda mitad por el gran éxito de las novelas históricas de Walter Scott y las de Charles Dickens en España.

En este sentido Eterio Pajares afirma que:

A principios del XVIII el dominio de la ficción correspondía a Francia. Posteriormente caminaría paralela a la trascendencia de la producción inglesa, y desde Scott hasta la actualidad, y con la sola excepción de la narrativa rusa del XIX, el dominio será inglés, compartido muchas veces con la novela francesa (Pajares 2006:12).

En efecto, algunos especialistas aluden a una "incipiente anglomanía" (Lafarga 2004: 210) en los albores del XIX, que favorecida por razones políticas y militares, tendrá como resultado una mayor importación de obras inglesas tanto líricas como narrativas.

En el contexto que acabamos de describir resulta comprensible que Rasselas, como texto novelístico y moralizante, atraiga el interés de los ilustrados y de generaciones posteriores. En efecto Rasselas constituye un caso excepcional en la recepción de la obra johnsoniana pues dispone de más versiones que ningún otro texto hasta la fecha, en especial teniendo en cuenta el auge de la novela como género popular durante los siglos XIX y XX.

Por otra parte, frente a la especificidad cultural y lingüística que caracteriza la obra crítica de Johnson, que versa fundamentalmente sobre autores de lengua inglesa, Rasselas es una obra de ambición universalista, repleta de enseñanzas sobre la naturaleza y las aspiraciones humanas, aplicables en cualquier cultura. La novela de Johnson carece de las alusiones directas a conflictos europeos en los que, como sucede en el poema "London", España sale mal parada ${ }^{20}$. Tampoco describe esta novela conductas reprobables que pudieses ser censuradas desde el punto de vista moral o religioso, por lo que su traducción era factible e incluso deseable. De hecho Rasselas, tiende a catalogarse como cuento filosófico, pues no se rige por los modelos narrativos que triunfan en Gran Bretaña y que conformarán la nueva novela realista, picaresca, epistolar o sentimental.

El contexto político de la época tampoco era especialmente favorable a la importación de obras británicas durante el siglo XVIII, un periodo en el que las relaciones hispanobritánicas fueron muy tensas. Desde la Guerra de Sucesión española (1702-1713) España se convirtió en un aliado fiel de Francia con la llegada al trono de un rey Borbón, Felipe $\mathrm{V}$, y mediante los sucesivos Pactos de Familia, España se convertiría también enemigo de los intereses británicos ${ }^{21}$. Gran Bretaña, por su parte, se adueñó de Gibraltar y Menorca

\footnotetext{
18 Adaptaciones del Robinson Crusoe se publican en 1798 (El nuevo Robinson de Campe y Los dos Robinsones o Aventuras de Carlos y Fanny, de Ducray-Duminil). El texto completo no se tradujo hasta 1835 (París), aunque hubo intentos en 1745 que no fructificaron. Idéntica suerte corrieron otras obras inglesa que fueron víctimas de la censura de la época (Joseph Andrews).

19 Viajes del capitán Gulliver a diversos países remotos (1793) a partir de versión francesa.

20 Al referirse al poema "London" Boswell dice que Johnson "allowed himself to look upon all nations but his own as barbarians: not only Hibernia, and Scotland, but Spain, Italy, and France, are attacked in the same poem". No es de extrañar que esta y otras obras de Johnson fueran silenciadas durante su época pues suponían un agravio innecesario al lector.

21 Los Borbones españoles del siglo XVIII fueron Felipe V (1700-1724 y 1724-1746), Luis I (1724), Fernando VI (1746-1759), Carlos III (1759-1788) y Carlos IV (1788-1808).
} 
mediante el Tratado de Utrecht y se beneficiaba así con el control del Mediterráneo, además de quedarse con el monopolio del tráfico de esclavos. Esta animadversión mutua continuó con motivo de las pretensiones de dominación de las colonias americanas por parte de españoles, franceses y británicos, quienes tras la Guerra de los Siete Años se quedaron con la mayor parte de las colonias francesas de América, a excepción de Luisiana cedida a España (1762). La Guerra de la Independencia de los EEUU supuso que España se granjeara la animadversión inglesa, al apoyar a las Trece colonias en su proyecto independentista. Por ese motivo, los panfletos políticos de Johnson, con numerosas alusiones a la superioridad británica frente a sus rivales, tampoco resultaban pertinentes para su traducción durante el XVIII y XIX.

A este entramado político habría que unir la tradicional oposición entre naciones protestantes y católicas. En una época donde el poder censor de la Inquisición era más que evidente aún, es comprensible que el número de obras importadas de Inglaterra fuese muy escaso y cuando la obra atravesaba la frontera se procedía a la adaptación de las obras a la cultura española o simplemente a la autocensura por parte de traductores e impresores ${ }^{22}$.

En resumen, la mayor parte de la obra de Johnson queda inédita en España a causa de su marcada especificidad cultural, lo que en inglés se denominaría "Englishness". Johnson es responsable de elaborar el canon literario inglés del XVIII que a penas había cruzado aún las fronteras españolas, donde el modelo a imitar en lo literario era aún el francés. No será hasta bien entrado el último tercio del siglo XX cuando su aportación a las Letras en lengua inglesa sea divulgada por los especialista en Filología inglesa y accesible al lector español. Por otra parte, en otros escritos, en especial los panfletos políticos, Johnson hubiese resultado impertinente incluso insultante, por ejemplo en el texto "Thoughts on the Late Trasaction Respecting Falkland's Islands" donde califica a los españoles de excesivamente tibios en su defensa de las Malvinas. En la España del XVIII, Johnson representaría una postura rival a los intereses políticos y comerciales de España en una época coincidente con el máximo esplendor de Gran Bretaña como potencia mundial, de ahí que no hubiese un interés en divulgar sus escritos políticos.

Sólo como resultado del enorme desarrollo que tienen los estudios de Filología inglesa en las universidades españolas como disciplina académica desde mediados de $\mathrm{s}$. XX, comienzan a publicarse de manera paulatina diversas muestras de la variada producción johnsoniana además de la conocida Rasselas. En ese proceso de rescate del autor destaca la traducción de su producción crítica, sus estudios sobre Shakespeare y sobre los poetas del XVII y XVIII. Recientemente el interés por el autor y su obra en España se ha intensificado como demuestran las ediciones de 2006 -Viaje a las islas occidentales de Escocia-, 2007 -con las dos ediciones de la Vida de Samuel Johnson y la edición de Rasselas- y 2009 -Escritos políticos-.

El lugar que ocupa Johnson en la cultura del XVIII bien justifica la continuación de esta labor de difusión de la obra de Johnson, aunque el acceso directo a las obras del autor en su propia lengua sea ahora algo al alcance de muchos. Parece que ahora el interés de

22 La Inquisición llegó a prohibir in totum la obra de Voltaire en 1762, elogiada por Feijoó y Luzán años antes (Lafarga 1982, citado en Saavedra y Sobrado 2004: 144). Si las obras de franceses ilustrados atravesaron las fronteras hispanas a duras penas, más difícil fue el tránsito de textos británicos, procedentes de una nación de herejes, hacia España. 
los investigadores y estudiosos está orientado hacia la difusión de facetas menos filológicas como son su perfil como pensador político, aspecto en realidad bastante complejo, y su experiencia como viajero del dieciocho, perspectivas novedosas sobre el autor que bien pueden interesar al historiador, al filósofo y al filólogo pero que estoy segura atraerán también la atención de cualquier lector medianamente perspicaz y curioso.

\section{REFERENCIAS BIBLIOGRÁFICAS}

Aguilar Piñal, F. 1996. Historia literaria de España en el siglo XVIII, Madrid: Trotta.

Álvarez Barrientos, J. 1991. La novela del siglo XVIII, Júcar, Madrid.

Bate, W. J. 1978. The Achievement of Samuel Johnson, University of Chicago Press, Chicago /London.

Bolufer Peruga, M. 2008. La Vida y la escritura en el siglo XVIII: Inés Joyce: Apología de las mujeres, Valencia: Publicacións de la Universitat de Valencia.

Boswell, J. 1986. The Life of Samuel Johnson LL.D. (1791), London: Penguin.

Greene, D. ed. 2000. Samuel Johnson. The Major Works, Oxford: Oxford University Press.

Korshin, P.J. 1999. "Johnson, the essay and The Rambler" en G. Clingham, The Cambridge Companion to Samuel Johnson, Cambridge University press, Cambridge, pp. 51-66.

DonaIRe, Ma L. y F. LAFARGa eDs. 1991. Traducción y adaptación cultural: EspañaFrancia, Oviedo: Universidad de Oviedo.

Hudson, N. 2003. Samuel Johnson and the Making of Modern England, Cambridge University Press: Cambridge.

Lafarga, F. y L. Pegenaute. eds. 2004. Historia de la traducción en España, salamanca. Ambos Mundos.

Pajares Infantes, E. 1996. "La teoría de la traducción en el siglo XVIII", Livius, 8, pp. 29-41.

Pajares Infantes, E. 2006. La novela inglesa en traducción al español durante los siglos XVIII y XIX: aproximación bibliográfica, Barcelona: PPU.

Ruiz Casanova, J. F. 2000. Aproximación a una historia de la traducción en España, Madrid: Cátedra.

SaAvedra, P. y H. Sobrado. 2004. El Siglo de las Luces: cultura y vida cotidiana, Madrid: Síntesis.

Stone, John. 2006. "On the Trail of Early Rambler and Idler Translations in France and Spain," The Johnsonian Newsletter 57.1, pp. 34-41. 


\section{Traducciones españolas de Life of Samuel Johnson de James Boswell}

Boswell, J. 1949. La vida de Samuel Johnson. trad. e introd. Antonio Dorta, Austral: Buenos Aires.

1998. La vida de Samuel Johnson, trad. e introd. Antoni Dorta, prólogo, F. Savater, Espasa: Madrid.

. 2007. La vida de Samuel Johnson, trad. José Miguel y Cándido Santamaría y María Pérez López de Heredia, Espasa Calpe, Madrid.

2007. La vida de Samuel Johnson, trad. y ed. Miguel Martínez-Lage, Acantilado, Barcelona.

\section{Traducciones en castellano y catalán de las obras de Samuel Johnson}

Johnson, S. 1798. El Príncipe de Abisinia: Novela[...]Va inserta[... una apología de las mugeres en carta original de la traductora, trad. Inés Joyes y Blake, Imprenta de Sancha, Madrid.

1813. Rasélas, príncipe de Abisinia: Romance, trad. Reverendo Don Felipe Fernández, Henrique Bryaer, Londres.

1834. Historia de Rasselas, príncipe de Abysinia, trad. Luis G. Cuevas, Imprenta Galván, México.

1860. Historia de Raselas, príncipe de Abisinia, (junto con Los compañeros de Jehú, de A. Dumas, trad. Juan Subirá) 2 vols. Trad. Marcial Busquets, Antonio San Martín, Madrid /Imprenta de Narciso Ramírez, Barcelona.

1945. Rasselas, principe de Abisinia, trad. Javier Zengotita, Reguera, Barcelona,

1951. La historia de Raselas (Príncipe de Abisinia), trad. y notas de Mariano Vedia y Mitre Kraft: Buenos Aires.

.1976. Raselas, (junto con Incógnita, de W. Congreve) trad. Enrique Blanco e introd. J.M. Martín Triana, Felmar, Madrid.

1982. La historia de Rassélas, príncipe de Abisinia, trad. de Elvio Gandolfo.

1991. La historia de Rassélas, príncipe de Abisinia, ed. y trad. Pollux Hernúñez, Alianza, Madrid.

2007. La historia de Rasselas, príncipe de Abisinia, trad. e introd. M Luisa Pascual, Berenice, Córdoba.

Vidas de los poetas ingleses, ed. trad. Bernd Dietz, Cátedra: Madrid, 1988. 

2003.

Prefacio a Shakespeare, trad. Carmen Toledano, Acantilado, Barcelona, 2004. Londres, trad. Valentín Carcelén, Agustín Gómez Flores, Albacete.

2004. Prefaci a les obres dramàtiques de William Shakespeare, trad. y ed. de Stone, J y E. Vidal, Universitat de Barcelona Publicacions y Edicions, Barcelona.

2006. Viaje a las Islas Occidentales de Escocia, ed. y trad. Agustín Coletes, KRK Ediciones, Oviedo.

2009. Escritos políticos, trad. Stella Mastrangelo, Katz Barpal, Buenos Aires/ Madrid. 